\title{
Memória em ação: a importância do Museu, da preservação e utilização da memória no espaço escolar
}

Memory in action: the importance of the museums, the preservation and how it is used in the schools

Fernanda Wisniewski Schoenardie* fe.wisniewski@gmail.com

Resumo: O presente artigo tem como objetivo apresentar o resultado de trabalho de pesquisa realizado no Ensino Médio Politécnico, na disciplina de seminário integrado. O mesmo discute e problematiza os museus como guardiões da memória local e a sua utilização como ferramenta de ensino e inspiração para a preservação da memória no espaço escolar. O estudo se baseia em uma observação de dois museus municipais, localizados nos municípios de Sapiranga e Nova Hartz, na região metropolitana do Rio Grande do Sul. Através deles, procurou perceber as diferentes formas que são utilizadas para a conservação das memórias locais e como os mesmos utilizam seu "poder simbólico" para significar as práticas dessas comunidades. Da mesma maneira, se pensa quais as possibilidades de estabelecer relações entre o museu e a escola e se ressalta a importância do espaço escolar como local de preservação da memória daquela comunidade que essa escola representa.

Palavras-chave: museu, memória, educação

Abstract: The objective of this article is to present the research made by students on high school, on the discipline integrated seminar. The article discuss and emphasize the problems of the museums as the guardians of the local history and how can be used as a tool for education and inspiration to the preservation of the memory in the school space. The study is based on an observation of two museums in the metropolitan region of Rio Grande do Sul located in the cities of Sapiranga and Nova Hartz. Through the museums it was searched the different ways that they were used to preserve the local history and how uses its Symbolic power'to give meaning to the actions of these communities. The same way, it is believed what are the possibilities to establish a connection between the museum and school and emphasize the importance of the school space as a place to preserve the memory of that city that this school represent.

Keywords: museum, memory, education

*Mestre em História pelo Programa de Pós-Graduação da Universidade do Vale do Rio dos Sinos (UNISINOS). Atualmente professora efetiva no Estado do Rio Grande do Sul. Este texto contou com a colaboração, no que tange à sua pesquisa, de Antrieli Flores, aluna egressa do Ensino Médio Politécnico do Instituto Estadual Mathilde Zatar, Sapiranga/RS. 


\section{Introdução}

Este trabalho é uma parte significativa de um projeto de pesquisa realizado no ano de 2015 , que tinha como principal objetivo atender a disciplina de Seminário Integrado ${ }^{1}$, componente curricular obrigatório do Ensino Médio Politécnico, do Instituto Estadual MathildeZatar, localizado no município de Sapiranga, no Rio Grande do Sul.

A ideia de se pesquisar essa temática surgiu em conversas informais com os alunos do terceiro ano do ensino médio da turma de 2015, da referida escola.Afinal este espaço,lida diretamente com a memória do aluno, em um sentido amplo. Seja para memorizar as fórmulas matemáticas, seja para conseguir estabelecer relações coerentes entre os conteúdos estudados. Comenta-se com frequência, a respeito da importância da memória para a sociedade. Memórias essas que podem ser de cunho pessoal, ou aquelas que caracterizam e dão significado a uma comunidade inteira. Segundo Costa (2007):

Um dos fenômenos mais trágicos das sociedades pós-modernas é a ausência (ou perda) de memória, seja ela individual ou coletiva. Sim, hoje o homem é um infeliz desmemoriado. Carente, necessitado e angustiado, pois há cerca de quarenta anos a pedagogia construtivista baniu a "decoreba" dos bancos escolares.

A necessidade de se preservar lembranças é algo cada vez mais comum nas sociedades contemporâneas, tendo em vista a crise da instituição memória, já mencionada. Por isso, a memória coletiva faz parte das grandes questões das sociedades desenvolvidas e das sociedades em vias de desenvolvi- mento e que são de grande importância para o fazer histórico dessas mesmas sociedades. Como nos lembra Roger Chartier (2010): "Sem dúvida, entre história e memória as relações são claras. O saber histórico pode contribuir para dissipar as ilusões ou os desconhecimentos que durante longo tempo desorientaram as memórias coletivas."

E a responsabilidade por resguardar e conservar esse patrimônio que é a memória, recai sobre os museus. Instituições que se multiplicam pelo Brasil, mas que em muitas, se não na maioria das vezes, são vistas pelo poder público e pela própria sociedade como um grande depósito de "velharias". Há um desconhecimento, ou até mesmo um "esquecimento intencional", sobre a real funcionalidade desse espaço e de sua importância para a comunidade na qual o mesmo está inserido e que teria o dever de representar.

O museu e a memória são inseparáveis em sua essência, e deveriam ser ferramentas indispensáveis no espaço escolar e na aprendizagem dos alunos. É através do museu, que o indivíduo pode se ver representado e participante dos processos históricos de formação da nossa sociedade. No entanto, como a maioria dessas instituições ainda é tratada de maneira equivocada por educadores e educandos e pouco valorizadas socialmente, pouco do seu real potencial é utilizado e os investimentos e políticas públicas destinadas a elas é insignificante, inviabilizando a realização de um trabalho de qualidade. Sobre a memória, Tedesco (2011, p. 166) coloca que "A memória é o resultado de um trabalho permanente no decorrer do tempo, no qual seus conteúdos são, de tempos em tempos conservados ou abandonados por grupos humanos concretos".

\footnotetext{
${ }^{1}$ No estado do Rio Grade do Sul, no ano de 2012, foi implantado o Ensino Médio Politécnico, através do Parecer 310/2012, do CEED. Nesta modalidade de ensino médio, há um componente curricular (disciplina) chamada de Seminário Integrado, e a mesma é voltada exclusivamente para o desenvolvimento e prática de pesquisa. De acordo com a sua nomenclatura, ela seria a disciplina integradora, onde o aluno coloca em prática os conhecimentos adquiridos, durante o desenvolvimento do seu projeto de pesquisa.
} 


\section{O museu e sua longa trajetória}

O museu é um espaço rico e cheio de possibilidades. Onde se preserva a memória de uma cidade, de um país, de um indivíduo. É um lugar de História ${ }^{2}$, que nos possibilita viajar no tempo e conhecer, mais intimamente, as memórias do lugar onde vivemos e do contexto social no qual estamos inseridos. Lá é o espaço para observarmos o passado, pensarmos o presente vivido e refletirmos sobre o nosso futuro.

Levando em consideração o grande potencial dessa instituição, investigar a sua trajetória foi de grande importância para a realização do trabalho de pesquisa mencionado. Desta forma, se buscou a compreensão do papel que o mesmo desempenha nas comunidades locais, nas quais o trabalho se concentrou.

É preciso também, pensar no poder exercido pelo museu. Principalmente, no sentido da já mencionada preservação da memória local.Quando Pierre Bourdieu (1989) nos fala sobre o "poder simbólico", ou seja, a tendência que toda e qualquer instituição desse caráter exerce ao selecionar e escolher um determinado tipo de memória a ser guardado, conservado, exposto e apropriado pelos seus frequentadores.

Quando visitamos um museu podemos pensar na transformação dos objetos, observando por exemplo como o processo da escrita foi se modificando ao longo da história, desde a invenção do papel até a criação do computador. Também na evolução urbana, como viviam nossos antepassados? E hoje, como vivemos? Em todo o mundo existem museus e eles recebem diferentes nomes, que variam em função do tipo de coleção que eles apresentam, temos os museus históricos, os museus de ciências, os museus de arte, as cidades museus, e os museus virtuais. Os acervos de museus especializados são muito diversificados, é possível que encontremos coleções de objetos de arte ou da cultura material de um povo, artefatos arqueológicos, de documentos gráficos e iconográficos, etc.

No Brasil, há uma legislação especifica que trata e regulamenta o funcionamento dessas instituições e ela foi criada recentemente. De acordo com a Lei $n^{0}$ 11.904, de 14 de janeiro de 2009, que instituiu o Estatuto de Museus,

Consideram-se museus, para os efeitos desta Lei, as instituições sem fins lucrativos que conservam, investigam, comunicam, interpretam e expõem, para fins de preservação, estudo, pesquisa, educação, contemplação e turismo, conjuntos e coleções de valor histórico, artístico, científico, técnico ou de qualquer outra natureza cultural, abertas ao público, a serviço da sociedade e de seu desenvolvimento.

A legislação brasileira se inspira nos estatutos contidos no ICOM (Comitê Internacional de Museus) definidos e aprovados pela $20^{\mathrm{a}}$ Assembleia Geral ocorrida em Barcelona na data de 6 de julho de 2001 "Museu" tem o segundo conceito "Instituição permanente, sem fins lucrativos, a serviço da sociedade e do seu desenvolvimento, aberta ao público e que adquire, conserva, investiga, difunde e expõe os testemunhos materiais do homem e de seu entorno, para educação e deleite da sociedade".

A perspectiva inicial está diretamente ligada a Grécia antiga, e seu significado relacionado ao templo das nove Musas e as divindades da memória. Na antiguidade clássica, ele não tinha a função de abrigar coleções de objetos, mas sim de ser um espaço para a contemplação e o exercício de estudos relacionados as

${ }^{2}$ Aqui refere-se a História no sentido da ciência histórica. 
ciências e as artes. Tereza Cristina Scheiner (2008), propõe que:

busquemos então a gênese do Museu não no templo, mas nas próprias musas, investigando a origem do termo na Grécia arcaica, em periodo anterior ao século VIII A.C., numa sociedade ágrafa, em que as antigas cosmogonias ainda não haviam cedido lugar às 'sophias'. Uma Grécia predominantemente rural, ligada a um passado micênico e cuja visão de mundo ainda não tendia a opor os diferentes planos do real: passado e presente, vida e morte, os homens e os deuses. Onde estaria o Museu, no plano da mitologia? Nos "bosques sagrados dedicados às deusas das artes liberais" (RIVIERE, 1989 , p. 48-49), ou na própria origem das musas? Filhas de Zeus e Mnemòsyne, as musas (palavras cantadas) são forças divinas. Elas têm o poder de tornar presentes os fatos passados e os fatos futuros, de restaurar e renovar a vida, de "fazer o mundo e o tempo retornarem à sua matriz original e ressurgirem com o vigor, perfeição e opulência de vida com que vieram à luz pela primeira vez" (HESÍODO, 1991, p. 71b).

Seguindo o curso da história, os museus vão ganhar notoriedade novamente a partir do século XV, quando o Renascimento cultural e cientifico, o ressurgimento das cidades, as atividades comerciais e o intercâmbio cultural, promovido pelas grandes navegações, vão incentivar a proliferação de coleções reais ou principescas e, posteriormente, dos chamados gabinetes de colecionadores. Essas primeiras coleções englobavam uma grande variedade de objetos, das mais diversas origens. Nelas se encontrava tudo aquilo que o colecionador coletava ao longo da vida, exibindo um pouco da enorme diversidade do mundo conhecido, e podia ter tudo, como: fósseis, insetos, livros antigos, animais empalhados, quadros e curiosidades, como objetos originários das Américas e da África, que estavam ainda em processo de descoberta pelos europeus e lhes promovia grande fascínio.

Hoje, museus são espaços acessíveis a toda a comunidade. Porém, antigamente os gabinetes eram abertos somente para amigos dos colecionadores, cientistas e pesquisadores, por exemplo, havia uma coleção de borboletas, ela ficava guardada, sem nenhuma visita. Até que em algum momento, as pessoas perceberam que as coleções mereciam um lugar especial, e assim elas ganharam espaço nos primeiros museus do mundo como o Museu Britânico e o Museu de História Natural, em Londres. Os primeiros museus, portanto, são resultado dos gabinetes de curiosidades, mas eram abertos apenas para "homens de saber", ou seja, apenas cientistas podiam visitar tais coleções, a regra valeu para outros museus abertos na época, como o de Belvedere, em Viena, de 1783, e o Museu de História Natural de Paris, aberto em 1793. Somente com a Revolução Francesa, no fim do século 18, após uma série de acontecimentos que mudaram o cenário político e social da França, que os museus se tornaram espaços abertos ao público, o primeiro com esse propósito foi o Louvre, aberto em Paris em 1793. Os primeiros museus científicos foram os de história natural, que reuniam animais e minerais que permitia que o sujeito que estivesse visitando o local tivesse a possibilidade de conhecer animais extintos, ou ecossistemas exóticos.

"Se a conjuntura da Revolução Francesa, em fins do século XVIII, traçou os contornos da acepção moderna de museu, esta se consolidaria no século XIX com a criação de importantes instituições museológicas na Europa" (JULIÃO, 2006).

No século 19, com o desenvolvimento da indústria e da tecnologia, surgiram os museus mais voltados para a tecnologia industrial. Seu objetivo era mostrar para o público todas as maravilhas científicas e tecnológicas que estavam sendo descobertas e produzidas. Às vezes, era permitido puxar alguns botões e alavancas, mas geralmente não podia encostar-se às novas invenções. 
Depois de muitos anos, surgiram os primeiros museus interativos, onde os visitantes finalmente tiveram a oportunidade de interagir com a exposição. Como por exemplo, o museu americano "Exploratorium”, aberto em 1969 em São Francisco, que tinha a proposta de aproximar o visitante dos objetos expostos. Depois de terem surgido na Europa e nos Estados Unidos, não demorou até que os primeiros museus de história natural chegassem ao Brasil. Ainda no século 19, foram abertos o Museu Nacional (1808), o Museu Paraense Emílio Goeldi (1866) e o Museu Paulista (1894), o primeiro foi criado no ano em que a família real de Portugal chegou ao Rio de Janeiro, para estimular o estudo das plantas (Botânica) e a dos animais (Zoologia), entretanto, continha um pouco de tudo, incluindo arte, antiguidades, minerais e artefatos indígenas. Ao longo do século 20, outros museus de ciências se espalharam pelo Brasil.

Mas, cabe ressaltar, que apesar de terem se tornado populares, museus destinados exclusivamente a ciência e a tecnologia, ainda são minoria em nosso país. A maioria das instituições brasileiras são destinadas a preservação de objetos históricos e memórias locais. No entanto, muito além ser compreendido como mero depósito, também se oportunizou que esses espaços fossem finalmente percebidos como instituições, através das quais, se torna possível o cruzamento de fronteiras em direção a outras aprendizagens. Ele tem a necessidade de ser usado como ferramenta de ensino, pois, não somente expõe peças, mas deixa claro que tipo de memórias aquela comunidade tem a intenção de preservar (PEREIRA; CARVALHO, 2010).
Se tem esquecido do quão importante é a relação entre o sujeito que está visitando o museu e o objeto que está exposto no local e as aprendizagens que ele pode proporcionar. Uma simples visita educativa de um grupo de estudantes ao local onde estão guardadas memórias, cria a oportunidade de se esclarecer o processo de transformação pelo qual aqueles objetos passaram ao longo dos anos. O quanto um simples jornal, por exemplo, pode representar diversas interpretações e usos culturais do passado, e que podem ser significativos para uma reflexão sobre o presente daquela população, que esse jornal representa. O material exposto no museu deve ser encarado como uma possibilidade de ferramenta na ação educativa, e que deve potencializar os significados, valores históricos e a memória coletiva (BOURDIEU, 1989).

\section{O museu, a memória, escola e o projeto de pesquisa}

Sapiranga é uma cidade interiorana, que se localiza na região metropolitana de Porto Alegre, no Rio Grande do Sul, e conta atualmente com cerca de 75 mil habitantes. Sua economia é baseada na produção industrial de componentes para calçados e sua colonização além da portuguesa, é basicamente alemã $\tilde{a}^{3}$. A história e a colonização da cidade estão inseridas em um contexto regional, ligado a colonização alemã e italiana, incentivada no contexto do início do período imperial no Brasil. Dom Pedro e a Imperatriz Dona Leopoldina, incentivaram a vinda de imigrantes germânicos para o sul do país. Em 1824, colonos alemães aportaram na cidade de São Leopoldo/RS e se espalharam pela região, dando origem a diversos municípios, sendo um deles Sapiranga.

\footnotetext{
${ }^{3}$ Em 1824, chegavam os primeiros imigrantes a São Leopoldo, cidade vizinha a Sapiranga e da qual a mesma foi distrito até a metade do século XX. Esses imigrantes se espalharam pela região, fundando diversos vilarejos e povoados, que mais tarde deram origem a diversos municípios. Para maiores informações consultar MAGALHÃES, Dóris Rejane Fernandes. Terras, senhores, homens livres, colonos e escravos na ocupação da fronteira no Vale dos Sinos. Tese de Doutorado. São Leopoldo: PPGH/UNISINOS, 2003.
} 
A memória dessa comunidade encontra-se "arquivada" e, parcialmente, preservada, na instituição municipal denominada "Museu Municipal de Sapiranga Adolfo Evaldo Lindemeyer". E podemos afirmar que a memória aqui representada é parcial, pois não são muitas as referências que tratam das migrações mais recentes, que ocorreram na cidade. Ou seja, ela enfatiza a memória do período de imigração alemã, que prevalece como a memória "oficial"4 do município. Nota-se que há um interesse em preservar essa memória da imigração, ou de certa maneira atrelada a este fato, como uma reconstrução permanente do passado. Sobre essa ideia de reconstrução, Tedesco afirma, "A memória coletiva não é ressurreição ou um reviver puro do passado enquanto tal, mas, sim, reconstrução em função do presente (NAMER, 1986). Os grupos precisam estar interessados, motivados, presentes e pertencendo; para isso, seu efeito e reconhecimento social pelos grupos são fundamentais (...)" (TEDESCO, 2011, p. 165).

A instituição está sediada no prédio que anteriormente, abrigou a estação de trem do município e leva esse nome em homenagem a um político local, ao vereador do município de São Leopoldo pelo distrito de Sapiranga no início da década de 1950. Esse senhor participou ativamente na campanha para a construção do Hospital municipal e foi um dos grandes incentivadores do processo emancipatório de Sapiranga que teve início em 1948 e culminou na criação do município em 28 de fevereiro de 1955. O Museu foi inaugurado em 1996, foi abrigado naquele espaço justamente porque ele representa o marco do desenvolvimento urbano desta localidade, que teve início a partir 1903, com a chegada dos trilhos de trem ao munícipio, neste ano. Segundo Dóris Rejane Fernandes Magalhães (2005):
A inauguração da estrada de ferro foi decisiva para Sapiranga. A comunidade tinha na estação Férrea, o ponto central da vila, onde as pessoas iam ver o trem chegar e partir. As ruas até hoje guardam o traçado da influência do largo da estação: a Rua 7 de setembro ao norte da rua 20 de setembro tem uma numeração e ao sul em direção a RS-239 tem outra; a rua Duque de Caxias e a Rua 28 de fevereiro iniciam sua numeração na Estação Férrea. Isso aconteceu porque o largo da estação era um forte divisor e hoje se transformou em praça e museu. (MAGALHÃES, 2005, p. 42)

O centro da então vila era o Largo da Estação, dela partiam ruas e ao seu redor se amontoavam os estabelecimentos comerciais e industriais que passaram a atrair moradores. Também a "Estação Sapyranga"5 era a atração nos finais de semana, a população se concentrava ali para ver o trem chegar e partir bem como ver amigos, conversar, namorar, etc. Por ser o marco inicial da área urbana do Município de Sapiranga, foi escolhido o local da antiga Estação Férrea para abrigar o Museu Municipal de Sapiranga que foi inaugurado em 02 de outubro de 1996. Em 2004, através da Lei 3361, o Museu passou a ter a atual denominação, já mencionada, e é um espaço que possibilita a volta ao passado, reafirma nossa relação com a cidade, nosso sentimento de pertencimento e de identidade ao lugar onde vivemos. Essa instituição tem por filosofia ser um centro de pesquisa, um espaço de cultura, um vínculo de ação educativa, tendo o Museu como objetivo de resgatar, estudar, documentar e difundir o patrimônio cultural de Sapiranga. O Museu realiza exposições temporárias e permanentes compostas pelo acervo de objetos antigos da primeira administração municipal, da estação ferroviária, a venda colonial e a casa do colono. Além disso, possui acervo fotográfico e bibliográfico. No mesmo

\footnotetext{
${ }^{4}$ Aqui se diz oficial pois, maioria dos historiadores locais se debruça sobre esse recorte de pesquisa, alterando apenas o recorte temporal, como é o caso da já mencionada Dóris Rejane Fernandes Magalhães ou do pioneiro Lúcio Fleck. Ambos dedicam suas trajetórias de pesquisa a temática da imigração alemã.

${ }^{5}$ Nomenclatura inicial, alterada com as transformações sofridas na língua portuguesa.
} 
são desenvolvidas pesquisas, através da prática de história oral, das quais a comunidade colabora com informações do passado do nosso município.

Fica claro então, que o referido museu possui localização privilegiada, desde seu princípio como estação e atualmente no centro da cidade, sendo de fácil acesso e propício para a visitação. No entanto, uma breve visita nos revela que mesmo dispondo de acesso facilitado, há um número pequeno de frequentadores e pouco investimento para que essa situação se altere. $\mathrm{Ou}$ seja, essa pouca visibilidade nos leva a refletir sobre qual o valor simbólico atribuído por essa comunidade a este local, e se de fato a população compreende a sua importância como guardião de suas memórias. Outra questão pode ser levantada, no que tange a que parcela populacional está sendo representada ali e se de fato ela abrange todas as camadas da sociedade, ou apenas a parte mais privilegiada dela (BOURDIEU, 1989, p. 10).

Sobre essa questão do tipo de memória preservada e das formas de armazenamento dessa memória, Tedesco menciona que:

A memória coletiva é, também, móvel em suas formas de manifestação e absorção/ armazenamento; não se reproduz tal e qual o fato presente no ato do acontecimento; é seleção, interpretação, transmissão de apenas certas representações do passado a partir do grupo em questão, de sua influência, de alguns de seus mediadores (Namer, 1986). Por isso a importância dos lugares de memória de forte poder simbólico e de pertencimento/ agregação coletiva, relevância, também, de ambientes sociais, dos quadros sociais, ou seja, dos ambientes de maior familiaridade, os quais vão ritualizando, comprometendo-se na recordação, acumulando conhecimentos, acervo linguístico, empatia e afetividade, criando, assim, referenciais de identidade e integração (BOSI, 1994). (TEDESCO, 2011, p. 164-165).
Chama a atenção também a questão da utilização deste espaço como ferramenta de ensino-aprendizagem. As escolas, principalmente as municipais, costumam levar seus alunos, em algum momento do período escolar, para conhecer o museu municipal. Mas, uma simples visita a exposição ou ao espaço como um todo, não permite que aquele individuo crie vínculo efetivo com o mesmo. Para tanto, para que haja uma verdadeira interação entre o visitante e o contexto histórico quem o mesmo representa é necessário que seja realizado um trabalho conjunto entre escola e museu, para que o aluno consiga atribuir significados aquele espaço, ao acervo que está disposto ali e compreenda que também faz parte da comunidade ali representada.

A visita educativa ao museu cria oportunidade para discutir a transformação dos objetos e seus usos no tempo, mas também cria uma oportunidade para a reflexão acerca do discurso do museu sobre os objetos. Por que razões a educadora do museu supõe não existirem mais mimeógrafos em uso nas escolas? Diversamente do que supõe o aluno, de que sua escola estaria - como o próprio objeto que opera - parada"no tempo, é possivel complexificar a compreensão da dinâmica de transformação dos objetos para além da linearidade passado-presentefuturo. (PEREIRA; CARVALHO, 2010).

Como a região possui diversos municípios com origem no mesmo processo de imigração foi importante observar a dinâmica de outras localidades com relação a seus espaços de memória e seus museus, para que se pudesse estabelecer uma comparação, mesmo que superficial, entre uma cidade e outra. Nesse sentido destaca-se o museu do município de Nova Hartz ${ }^{6}$, Guilherme Albino Muller, que teve sua inauguração no dia 03 de dezembro de 1999. Neste município, o museu é um local querido tanto para as pessoas que são nascidas no município, como para aqueles que vieram de fora, os

\footnotetext{
${ }^{6}$ O município de Nova Hartz é vizinho do município de Sapiranga, tendo inclusive, feito parte da configuração deste até o ano de 1988 , quando conseguiu sua emancipação. É uma cidade pequena, que comporta aproximadamente 19.000 habitantes, segundo o IBGE. Sua formação também é fruto do processo de imigração alemã, em 1824, inclusive levando no nome a homenagem a família Hartz, que foi a fundadora da cidade.
} 
cidadãos que pertencem as famílias tradicionais da cidade observam sua história sendo contada no Museu e as que vieram de fora têm oportunidade de conhecer a história da cidade todo.

O acervo do museu é composto por peças que foram doadas pela comunidade local. E ao visita-lo é possível compreender a evolução econômica pela qual o município passou com a chegada dos imigrantes, a implantação das propriedades familiares e mais tarde (especificamente a partir da década de 1950) o início da produção calçadista. O Museu trabalha com projetos pedagógicos, que envolvem principalmente alunos do ensino fundamental. Em parceria com as escolas e professores, o museu desenvolve atividades como jogos, palestras, passeios, pesquisas com materiais acessíveis e práticos, projetos de história oral, entrevistando antigos moradores que contam suas memórias e consequentemente a história da cidade.

Além disso, cabe ao museus e seus responsáveis a organização de Seminários de Preservação do Patrimônio Histórico de Nova Hartz, o estabelecimento de parcerias com outras instituições para a promoção de Saraus literários, exposições temáticas temporárias em uma sala do Museu e em outros estabelecimentos, desfiles temáticos, e de propor e ajudar na coordenação do Projeto Cultural Roda D'água que busca preservar o Patrimônio histórico e natural do município, tendo o turismo sustentável como forma de dinamizar a preservação.

Com tantas atividades e interação com a comunidade a qual pertence, a instituição de patrimônio de Nova Hartz realmente demonstra que um museu pode sim ser um lugar alegre, interativo, moderno e muito divertido. Mesmo que o acervo seja basicamente um retrato do processo de colonização alemã, podemos encontrar nele uma identificação com a população que representa. Ele é formado por utensílios domésticos e agrícolas, instrumentos musicais, objetos pertencentes a escolas e igrejas, roupas, e fotografias.

Uma breve visita ao espaço permite perceber que o objetivo principal da instituição não é somente de que os alunos visitantes apreciem os objetos expostos de maneira distante, mas que os mesmos interajam e aprendam com cada um deles. $\mathrm{O}$ formato da apresentação aproxima essas crianças da história de seu município e de suas origens e cria um laço, que na maioria das vezes faz com que eles retornem ao museu trazendo seus familiares e dando sentido a existência dessa instituição.

Observando que o museu e a escola podem e devem andar juntos, é preciso aproximar essas instituições. No Instituto Estadual Mathilde Zatar, onde esta pesquisa teve início, pensou-se em valorizar o processo de conservação e reativação da memória deste espaço ${ }^{7}$, que faz parte de uma comunidade (Bairro São Luiz), na periferiado município.

Essa instituição de ensino surgiu em 07 de setembro de 1956 foi construído pelo prefeito de Sapiranga, Edwin Kuwer ${ }^{8}$, o Grupo Escolar Municipal São Luiz, localizada na rua Presidente Kennedy, 1328 - Bairro São Luiz. Em 07 de fevereiro de 1957 a escola passou da administração municipal para a estadual, vindo então chamar-se Grupo Escolar nos Subúrbios de Sapiranga. Somente em 06 de maio 1965, quando a escola passou

\footnotetext{
${ }^{7}$ No ano de 2016, o Instituto Estadual Mathilde Zatar completa 60 anos de existência. Por iniciativa da comunidade escolar, diversos projetos serão desenvolvidos ao longo do ano, com o objetivo de dar visibilidade aos atores envolvidos nesse processo histórico e demonstrar a importância da instituição para a comunidade em que ela está inserida.

${ }^{8}$ Primeiro prefeito eleito do munícipio de Sapiranga.
} 
por uma nova mudança, de acordo com o decreto estadual $\mathrm{n}^{\mathrm{o}} 17287$, que passou a chamar-se Grupo Escolar Mathilde Zatar. ${ }^{9}$

Foi somente em 31 de março de 1980, que o grupo escolar passou a chamar-se Escola Estadual de $1^{\circ}$ Grau Incompleto Mathilde Zatar. Com o auxílio dos pais foi construído muro, foram comprados instrumentos para a implantação da banda, enfim os pais colaboravam para a manutenção e conservação da escola. A merenda era feita por duas merendeiras e os ingredientes para a merenda eram doados pelos pais dos alunos.

É possível perceber o grande carinho e envolvimento com a escola por parte da comunidade envolvente, após a realização de conversas com ex-alunos, era impossível não notar o quanto as memórias referente a escola e ao período escolar de cada um ainda estão vivas. As frases saudosas se multiplicam quando se solicita que descreva a escola em que estudaram: "Meus primeiros passos em direção ao meu sonho"; "É uma escola excelente"; "Uma grande e dedicada família"; "Casa". Essas, entre tantas outras, deixam clara a importância que aquela comunidade atribui a esse espaço. Ou seja, essa comunidade escolheu guardar estas memórias e este espaço lhes traz um sentimento de pertencimento àquele local.

O projeto de pesquisa iniciado no ano de 2015, foi intitulado de "Museu: conhecer, construir e aprender", e foi proposto para atender a disciplina de seminário integrado, componente curricular do Ensino Médio Politécnico, no Rio Grande do Sul. Esta disciplina estimula os alunos a promoverem construção de conhecimento através da realização de pesquisa aplicadas, que preferencialmente sejam voltadas a resolver problemas da própria comunidade.

A proximidade com a comemoração do aniversário de sessenta anos da instituição de ensino Mathilde Zatar, a ser realizado em 2016, incentivou a promoção de diversos projetos de resgate da memória desse espaço, já entre os meses de maio e dezembro de 2015. Essas iniciativas, foram de encontro com a elaboração da pesquisa que originou esse trabalho. No mês de novembro o trabalho foi apresentado em um feira de ciências, em nível municipal, e foi premiado com o terceiro lugar na categoria de pesquisa em Ciências Humanas.

Com o intuito de descobrir a real função da preservação da memória, e das instituições que se dedicam exclusivamente a esta tarefa, inicialmente observou-se o museu local (Sapiranga), e posteriormente se buscou na região outro modelo (Nova Hartz), para que se pudesse comparar o tratamento que cada município dava a sua memória coletiva e como cada um tratava de seu "armazenamento". Nesse sentido, Tedesco nos diz que:

Pierre Nora (1978) diz que há no cenário moderno uma proliferação de memórias coletivas, em geral, motivadas pelos meios midiáticos e pelos recursos técnicos disponiveis, que intencionam reproduzir, analítica e objetualmente, formatos de vida social. Os lugares que convencionamos para guardar e conservar são expressão da ausência de meios que foram perdidos. No fundo, essas memórias coletivas são expressão e manifestação de sentimentos do passado e possibilidade de inventariar lugares para a sua preservação visual e histórica. (TEDESCO, 2011, p. 29)

As observações permitiram a compreensão das potencialidades do Museu como uma importante ferra-

\footnotetext{
${ }^{9} \mathrm{O}$ nome da escola foi escolhido em homenagem à grande jornalista Mathilde Zatar, uma mulher admirável, um exemplo de espírito de liderança e dinamismo, amava ao próximo. Mathilde nasceu na cidade de Uruguaiana, no dia 28 de agosto de 1918, filha de Elias e Emma Zatar, era de uma família grande, de sete irmãos, sendo quatro mulheres, Adélia, Isabel, Emma e Carmem Maria, e três homens, Jaime, Mário e Jacinto que se dedicaram a vida no comércio. Mathilde uma renomada jornalista, durante a sua vida, dedicou-se não só ao jornalismo, mas também às obras sociais. Mas, principalmente, a assuntos relacionados com a educação. No dia 07 de agosto de 1964, a jornalista faleceu no Rio de Janeiro aos 46 anos de idade, após ter ali se submetido a uma intervenção cirúrgica, tendo sido sepultada na cidade de Porto Alegre, onde morou e atuou durante vários anos.
} 
menta no processo de ensino, mas também demonstraram as limitações a que muitas dessas instituições são submetidas e por outro lado, a falta de interesse por parte da comunidade, em frequentar esses locais. Relegando a estes espaços um caráter de esquecimento, e desconhecimento.

O desenvolvimento do trabalho de pesquisa, permitiu também, observar que falta um caráter atrativo, principalmente para os jovens, no que se refere ao Museu. O fácil acesso a recursos tecnológicos e a dinâmica da juventude atual, afastam o interesse dos jovens deste local. Este é, sem dúvida, o maior prejuízo percebido ao longo do percurso da pesquisa.

\section{Considerações Finais}

Este artigo é resultado de um trabalho de pesquisa, iniciado no terceiro ano do ensino médio, de uma escola pública de uma cidade do interior do Rio Grande do Sul, com o intuito de atender a uma disciplina escolar, mas tornou-se algo muito maior. Ampliou os horizontes para a compreensão da importância de resgatar e de valorizar as memórias e a utilizar de maneira efetiva os espaços que se dedicam a preservar essas memórias locais: os museus.

O trabalho de pesquisa também possibilitou que a questão da valorização da memória local ganhasse destaque dentro da comunidade escolar em questão. Despertando maior interesse, tanto nos alunos, quanto no corpo docente, no que refere-se a preservação e conservação da memória da comunidade escolar.
Inicialmente, a pesquisa se concentrou em refletir sobre o processo de surgimento e evolução da instituição museológica e sua função social, posteriormente passou-se a uma crítica sobre a sua efetiva utilização, principalmente no munícipio de Sapiranga, como referência na preservação da memória dessa cidade e a forma como essa memória é transmitida aos seus moradores e como a mesma é compreendida por eles.

Comparando o museu desta cidade com o museu de Nova Hartz, foi possível perceber que o mesmo não é utilizado em sua totalidade, deixando a desejar neste sentido. No entanto, foi possível perceber também, que é necessário repensar o museu em ferramenta valiosa de apoio à escola e ao ensino. Mesmo sem os recursos, ou sem a valorização almejada por esses espaços, os mesmos exercem grande importância em suas comunidades, quando compreendidos em sua essência.

Além disso, foi pensando criticamente sobre a instituição museu, que se tornou possível avaliar novas perspectivas para a construção de uma memória coletiva significativa, envolvendo novos atores, como o espaço escolar. Esse local pode, e deve, ser visto como uma possibilidade de formação, representação e preservação de memória de uma comunidade muito especifica, como a escola, por exemplo. Demonstrando que o cuidado e responsabilidade com a manutenção da mesma, não reside somente nos museus, mas sim no cerne das comunidades, que selecionam e escolhem as memórias que tem a intenção de preservar e transmitir as próximas gerações. 


\section{Referências bibliográficas}

BOURDIEU, Pierre. O poder Simbólico. Rio de Janeiro: Bertrand Brasil, 1989. Disponível em:

$<$ http://lpeqi.quimica.ufg.br/up/426/o/BOURDIEU_Pierre_O_poder_simb\%C3\%B3lico.pdf>. Acesso em: 15 nov. 2015.

CHARTIER, Roger. A história ou a leitura do tempo. Belo Horizonte: Autêntica Editora, 2010.

COSTA, Ricardo. História e memória: a importância da preservação e da recordação do passado. In: Sinais - Revista Eletrônica - Ciências Sociais. Vitória: CCHN, UFES, Edição n.02, v.1, Outubro. 2007. pp 02-15.

JULIÃO, Letícia. Apontamentos sobre a história do Museu. In: Caderno de diretrizes museológicas I. Brasília: Ministério da Cultura. Instituto do Patrimônio Histórico e Artístico Nacional/ Departamento de Museus e Centros Culturais, Belo Horizonte: Secretaria de Estado da Cultura/ Superintendência de Museus, 2006. 2. ed.

LEMOS, Carlos A. C. O que é patrimônio histórico. São Paulo: Editora Brasiliense S.A., 1981.

MAGALHÃES, Dóris Rejane Fernandes. Terras, senhores, homens livres, colonos e escravos na ocupação da fronteira no Vale dos Sinos. São Leopoldo Tese (Doutorado), PPGH/UNISINOS, 2003.

MAGALHÃES, Doris Rejane Fernandes. Sapiranga 50 anos de município. Mais de 200 de história. Porto Alegre: Alcance, 2005.

PACHECO, Ricardo de A. Educação, memória e patrimônio: ações educativas em museu e o ensino de história. In: Revista Brasileira de História, São Paulo, v.30, n. 60, p. 143-154, 2010. Disponível em: <http://www.scielo.br/ pdf/rbh/v30n60/a08v3060.pdf>. Acesso em: 20 out. 2015.

PEREIRA, Júnia Sales; CARVALHO, Marcus Vinicius Corrêa. Sentidos dos tempos na relação museu/escola. In: Cad. CEDES, vol. 30, n. 82, Campinas, set./dez. 2010. Disponível em: <http://www.scielo.br/scielo.php? script $=$ sci_arttext\&pid=S0101-32622010000300008>. Acesso em: 15 nov. 2015.

SHEINER, Tereza Cristina. O museu, a palavra, o retrato e o mito. In: Revista eletrônica do Programa de Pós Graduação em Museologia e Patrimônio - PPG - PMUS/ MAST. vol. 1, n. 1, jul./dez. 2008. Disponível em:

$<$ http://revistamuseologiaepatrimonio.mast.br/index.php/ppgpmus/article/download/6/19>. Acesso em: 20 out. 2015 .

TEDESCO, João Carlos. Passado e presente em interfaces: introdução a uma análise sócio-histórica da memória. Passo Fundo: Ed. Universidade de Passo Fundo; Xanxerê: Ed. Universidade do Oeste de Santa Catarina; Porto Alegre: Suliani Letra e Vida, 2011. 